\title{
Work Requirements in Public Housing: Impacts on Tenant Employment and Evictions ${ }^{1}$
}

\author{
William M. Rohe \\ Michael D. Webb \\ Kirstin Frescoln \\ Center for Urban and Regional Studies \\ University of North Carolina at Chapel Hill
}

September 2015

\begin{abstract}
In recent years, many have debated adopting work requirements in the Public Housing Program, and eight public housing authorities have implemented these policies through the flexibility provided by the Moving to Work demonstration. One such agency - the Charlotte Housing Authority (CHA) - has adopted a work requirement across five (of its 15) public housing developments that mandates heads of household work 15 hours per week or face sanctions. This paper evaluates this policy and presents the first empirical comparison of employment and eviction rates between those subject to the work requirement and a comparison group not subject to the policy. We find that, following work requirement enforcement, the percentage of households paying minimum rent (a proxy for employment) decreased relative to the comparison group. Analysis of additional data on both employment and hours worked indicates similar employment gains, but no increase in average hours worked. We find no evidence that work requirement sanctions increased evictions, and only modest evidence that enforcement increased the rate of positive move-outs. Surveys of CHA residents indicate that a large proportion support work requirements in public housing. While our findings clearly support the effectiveness of the CHA's work requirement, we caution against imposing such a requirement before more research is conducted.
\end{abstract}

\footnotetext{
1 This research was supported by the Charlotte Housing Authority under grant 09-1739. We would like to thank Rachel McCarthy and Kristin Porter for proofreading assistance in addition to Sydney Corn for help with data management. We would also like to thank LaRae Baumann, Ja'Shaun Brailey, Gainor Eisenlohr, and Gwen Isley at the CHA for providing administrative data and answering our many questions.
} 


\section{Introduction}

One of the often-heard criticisms of the Public Housing and Housing Choice Voucher (HCV) Programs in the U.S. is that they actively discourage employment among program participants. ${ }^{2}$ Because they base rents on 30 percent of adjusted income, 30 cents of every additional dollar earned by participants goes to increased rent before work-related expenses and deductions in other social benefit programs are considered. Moreover, when incomes rise to a certain level, housing assistance is phased out entirely. Calculating rents thusly may be one reason why only 55 percent of work-able (that is, non-elderly and non-disabled) public housing tenants have any wage income - and among those, most earn below the federal poverty level (Schwartz, 2015).

Since the mid-1980s, Congress has introduced several demonstration programs and policy reforms to increase employment among public housing families. As will be described in more detail below, these efforts have sought to overcome disincentives to work by offering positive enticements such as escrow accounts and work preparedness services - e.g., employment counseling, education, and job training - that address barriers to employment. The success of these programs in increasing employment and wages has been limited, however, due to a combination of constrained capacity and lack of resident interest (Ficke \& Piesse, 2004; Rohe \& Kleit, 1999).

One new approach - so far available only to the 39 public housing authorities (PHAs) participating in the Moving to Work demonstration - is imposition of work requirements, which require work-able public housing residents to work a minimum number of hours per week (Webb, Frescoln, \& Rohe, 2015). If residents fail to meet the requirement, sanctions - such as rent increases and eventual eviction - are imposed. Many PHAs couple work requirements with supportive services like job training, educational assistance, and childcare and transportation subsidies to help residents obtain and maintain employment. These policies may also be phased in over time to provide residents with an extended opportunity to comply with the new requirements.

This paper presents the first empirical analysis of the impacts of a work requirement on employment. More specifically, it assesses a work requirement introduced by the Charlotte Housing Authority (CHA) on residents living in five of its 15 public housing (Section 9) developments on: (1) the work efforts of public housing residents subject to it; (2) the rates of sanction and eviction resulting from its enforcement; and (3) tenants' attitudes toward the work requirement.

\footnotetext{
${ }^{2}$ For brevity, we refer to the Public Housing and HCV Programs as the "public housing program" throughout the paper. We also refer to participants in these two programs as "public housing residents." When discussing development-based public housing (i.e., Section 9) exclusively, we will refer to these as "public housing (Section 9) developments."
} 


\section{Arguments for a work requirement}

Policy-makers, public housing administrators, and other stakeholders have offered several arguments in favor of work requirements: (1) to counteract the negative work incentives inherent to the program; (2) to increase the financial health of public housing authorities; (3) to serve more low-income families in need of subsidized housing; and (4) to increase economic diversity and establish an environment of work among residents in low-income housing developments.

\section{Negative work incentives}

Many policy-makers and much of the public believe that work-able public housing residents should make every effort to increase their incomes so they no longer need housing subsidies. Moreover, there is concern that some public housing residents are not doing that. As stated earlier, recent figures show that almost half of households classified as having a work-able adult report no wage income. Some critics argue that relatively low rates of employment among work-able public housing residents result from lack of personal motivation (Mead, 1998). Michael Leavitt, Secretary of Health and Human Services under George W. Bush, invoked the personal motivation perspective by arguing that "[a] critical benefit of strong work expectation and activities is the ability to acclimate recipients to a working lifestyle - not simply learning how to do a specific job, but to learn through experience what it takes to be employed and remain employed" (Fording, Schram, \& Soss, 2013, p. 646).

Other critics highlight aspects endemic to the public housing program that undermine work incentives, thus causing relatively low employment rates among residents. First, program participants feel less pressure to work if housing - one of life's basic needs - is ensured (Olsen, Tyler, King, \& Carrillo, 2005; Susin, 2005). Second, public housing rents are based on a percentage of household incomes, ${ }^{3}$ which, in effect, levies a substantial tax on earnings (Riccio, 2008). These higher rents - coupled with reductions in other benefits that often accompany wage increases - may offset any additional income earned (Newman, 1999).

By imposing work requirements, PHAs hope to overcome these disincentives by requiring residents to gain employment to continue living in public housing. PHAs see work requirements as providing a strong disincentive to unemployment for work-able program participants - particularly when paired with rent reforms that allow residents to retain more of their income increases.

\footnotetext{
${ }^{3}$ Except in some situations in the HCV Program, public housing rents are set at 30 percent of the household's income, adjusted for deductions like childcare and out-of-pocket medical expenses.
} 


\section{PHA financial health}

Another argument for work requirements is that they will increase PHAs' financial health at a time of declining federal subsidies. Since 1969 - when the federal government stipulated that rents must be based on a percentage of tenants' adjusted incomes - the U.S. Department of Housing and Urban Development (HUD) has provided operating subsidies to fill the gap between tenant rent receipts and the costs of operating the units (von Hoffman, 2012). The importance of these subsidies has grown over time. By 2003, operating subsidies made up about half of a typical PHA's operating budget (McClure, Schwartz, \& Taghavi, 2015; Stockard et al., 2003). In recent years, however, Congress has consistently allocated less operating support to PHAs than called for under the HUD formula. Thus, PHAs must either find other sources of funds to close this gap or reduce spending (Levitz, 2013). If effective, work requirements can increase tenant incomes - and, as a result, rent receipts - thus improving PHAs' bottom lines.

\section{Serving more families}

Work requirements may also open up the limited supply of public housing for other low-income residents. A key feature of the public housing program is that it is not an entitlement: qualified households are not guaranteed to receive assistance. Because Congress has consistently underfunded public housing operating subsidies, only approximately one-quarter of all qualified households receive housing assistance (Schwartz, 2015). As a result, most PHAs have long waiting lists, and households can wait 10 or more years to receive assistance. Insufficient funding further means that millions of households receive no assistance and are living in "worst case" housing conditions - defined as those paying more than 50 percent of their incomes for rent or living in dilapidated or overcrowded housing (Steffen et al., 2015). One way to serve more families is to cycle recipients through the program more rapidly. Graduating people out of public housing and off housing assistance opens up opportunities for those on waiting lists. Thus, to the extent that work requirements lead to income increases and subsequent moves to unsubsidized housing, the policy will result in more eligible families being served.

\section{Increase economic diversity and create a culture of work}

Another argument for work requirements is that they can help diversify the income characteristics of public housing residents and lessen the negative impacts of concentrated poverty on individuals and communities (Falk, McCarty, \& Aussenberg, 2014). The public housing program has always been targeted to households that could not reasonably afford private-market housing. Over time, however, federal proscriptions for who should have priority for the limited amount of housing assistance have changed dramatically, resulting in a concentration of very low-income households living in public housing (Section 9) developments (von Hoffman, 2012). Although more recent federal policy has sought to 
address this concentration, as of 2013, the annual average income of public housing households was only $\$ 13,724$, and only 18 percent had incomes over $\$ 20,000$ (Schwartz, 2015).

Critics of public housing assert that it both concentrates high-poverty families and is racially segregated, and numerous studies have demonstrated that spatially-concentrating very low-income households can exacerbate crime and other behaviors commonly associated with the "culture of poverty" (Briggs, Popkin, \& Goering, 2010; Goetz, 2013; Lewis, 1959; Massey \& Denton, 1993; Reingold, Van Ryzin, \& Ronda, 2001; Turner, Popkin, \& Rawlings, 2009; Vale, 2000; Wilson, 1987). Further, many believe that individuals will be more likely to engage in work and other socially-responsible behaviors if they are living in a community that exhibits and values these behaviors (Graves, 2011; Joseph, Chaskin, \& Webber, 2007; Kleit, 2005). If successful, work requirements can increase employment in public housing, thus reducing concentrations of poverty and creating a social milieu of work.

\section{Arguments against a work requirement}

Not everyone, however, is supportive of public housing work requirements. Social justice advocates argue that safe and affordable housing should be a basic human right and that policies that interfere with this right - such as work requirements - are unjust. The National Low Income Housing Coalition, for example, has come out firmly against them, arguing that "self-sufficiency contracts and time limits should [not] be allowed in federal housing safety net programs" (Couch, 2014, 4-18-4-19). The primary arguments against public housing work requirements are that: (1) they infringe on individuals' "right to housing;" (2) the characteristics of public housing residents present major obstacles for finding and maintaining employment; and (3) work requirements may lead to an increase in homelessness.

\section{A right to housing}

In recent years, many activists have called for a "right to housing" - that is, the belief that everyone has the right to decent, safe, and secure housing regardless of personal circumstances (Bratt, Stone, \& Hartman, 2006; Bratt, 2002; Edgar, Doherty, \& Meert, 2002; Stone, 1993). From this perspective, imposing work requirements as a condition of housing assistance is seen as unfair. Rachel Bratt, a prominent advocate for such a right, wrote "I would only favor work requirements in public housing if everyone who gets some kind of housing subsidy (including those who take the home mortgage interest deduction) is subject to the same requirements" (emphasis in original) (Bratt, personal communication, July 22, 2015). Bratt asks, "What is the justification for singling out a poor public housing resident who may, in fact, get a lower subsidy amount than a wealthy homeowner [who takes the mortgage interest deduction]?' Moreover, she argues that any kind of work mandate should be supported by a comprehensive set of services including caseworkers and job counselors (Bratt, personal 
communication, July 22, 2015). Evicting non-compliant residents - who are already low-income - is seen by many resident advocates as unfairly targeting already vulnerable families (Fischer, 2015).

\section{Barriers to employment}

Public housing residents often have personal characteristics - such as limited education, poor health, and limited work histories - that make it difficult to find and keep employment, even in a good economy. Tenant advocates argue that: “... tenants should not have to do x, y, or z unrelated to complying with the housing-related terms of their lease to maintain their housing assistance. Work requirements threaten the housing stability of tenants, who may well have erratic working experiences but nonetheless need housing" (Linda Couch, personal communication, July 22, 2015). Evidence from work requirements imposed under Temporary Assistance to Needy Families (TANF) indicates that sanctioned households face more barriers to compliance: they have more children, less work experience, an ill or disabled housing member, or other significant obstacle to employment (Hasenfeld, Ghose, \& Larson, 2004).

\section{Increased homelessness}

Another argument against work requirements is that, as PHAs evict non-compliant families, they may substantially increase homelessness. This, then, may shift the burden of housing these families to local homeless assistance agencies, resulting in a need for increased public funds to re-house these households. It may also have dramatic short- and long-term impacts on social services needed by evicted households. In discussing the possible impacts of work requirements and time limits, Fischer (2015) suggests that they could significantly undermine the voucher program's effectiveness in reducing homelessness, overcrowding, and housing instability.

\section{Prior efforts to address employment among public housing tenants}

Concerns about the concentration of unemployment and poverty in public housing have been long-standing, and HUD has introduced several policies and programs to address them. Unlike punitive work requirements, most of these initiatives have either incentivized employment or increased the employability of public housing residents. These efforts, however, have been limited in scope and effectiveness (Ficke \& Piesse, 2004; Rohe \& Kleit, 1999).

One set of initiatives falls into the category of "self-sufficiency" programs, in which PHAs collaborate with local service providers to offer education, job training, and other supports so that program participants can increase their incomes and move to unsubsidized housing. Introduced in 1984, the first such initiative - Project Self Sufficiency - provided additional vouchers to PHAs that developed programs to help residents achieve "economic independence," defined as no longer requiring federal housing assistance (Office of Policy Development and Research, 1987). Implemented locally by a coordinating committee of representatives from the PHA and local service providers, each program conducted 
individualized assessments of participants and provided case managers to help participants secure services. The Gateway Transitional Families Program incentivized employment by diverting rent increases following wage gains into escrow accounts that participants could use to support their work or training efforts and move to unsubsidized housing (Rohe \& Kleit, 1997).

Experience with these demonstrations led to the development of the Family Self-Sufficiency (FSS) Program, authorized in 1990 and still active today. Like earlier self-sufficiency programs, FSS escrows some rent increases that result from wage gains (Rohe \& Kleit, 1999). In fiscal year 2012, 68,548 HCV recipients and 14,386 public housing residents participated in FSS (Scirè, 2013). While these figures are not trivial, they represent a very small percentage of work-able public housing residents. Furthermore, evaluations of FSS indicate that a large percentage of participants leave the program prior to completion (de Silva, Wijewardena, Wood, \& Kaul, 2011). HUD also currently supports two smaller self-sufficiency programs: the Resident Opportunity and Self-Sufficiency (ROSS) and Community and Supportive Services (CSS) program for HOPE VI grantees.

Another approach to addressing low employment rates among public housing residents is embodied in the Jobs-Plus Demonstration, initially implemented in six different sites. Introduced in 1996, Jobs-Plus seeks to create a community-wide culture of work by providing residents with job training and job placement assistance. Like FSS, Jobs-Plus also delays rent increases due to increased incomes; some sites charged residents flat rents that increased over time, while others reduced the percentage of income that residents paid toward rent (Bloom, Riccio, \& Verma, 2005). Case managers help residents locate both training and employment opportunities. Finally, each Jobs-Plus site undertook several activities to strengthen community support for work. These included the development of peer support groups, workrelated information-sharing, and other "work-supporting social capital." HUD recently funded another pilot program that replicates the basic program model in nine PHAs (Castro Ramirez, 2015).

Congress also addressed employment among public housing residents in several provisions of the 1998 Quality Housing and Work Responsibility Act (QHWRA, P.L. 105-276). Community Service and FSS provisions within QHWRA require residents of public housing (Section 9) developments (but not HCV holders) to perform eight hours of community service or participate in a self-sufficiency program for at least eight hours monthly. ${ }^{4}$ QHWRA directs PHAs to not renew leases for those failing to satisfy the requirement, although households are given three months to come into compliance. Moreover, PHAs must seek cooperative agreements with local agencies to provide services and help residents comply with

\footnotetext{
${ }_{4}^{4}$ The act also includes a long list of persons who are exempt from this requirement, including those who are already working, in a training program, elderly or disabled, and other groups.
} 
community service requirements. Because QHWRA does not explicitly require paid employment, however, it falls short of what work requirement supporters would like to see.

To incentivize employment, QHWRA also includes several provisions that impact rents paid by residents. First, it authorizes PHAs to set minimum monthly rents - no greater than $\$ 50$ per month - and agencies must develop a process for determining hardship exemptions for minimum rents; possible hardships include a death in the family and the "prospect of eviction" (Falk et al., 2014). Second, QHWRA also authorizes transitional ceiling rents - where rents are capped at an upper-limit for a specified period of time - to allow households to save funds for the costs of moving into unsubsidized housing. Finally, QHWRA allows PHAs to disregard wages from household members who were previously unemployed or on TANF for up to 12 months, and then to phase in rent increases over time. This is designed to, at least temporarily, mitigate the negative work incentives for some public housing residents.

\section{Work sanctions in the TANF program}

Given the lack of prior research on impacts of public housing work requirements, we turn to the public welfare field to see what might be expected. Requirements that welfare recipients seek employment have long been part of welfare programs (Hasenfeld et al., 2004). The Personal Responsibility and Work Opportunity Reconciliation Act of 1996 (PRWORA, P. L. 104-193, commonly known as "welfare reform"), however, substantially strengthened both work requirements and sanctions for the Temporary Aid to Needy Families (TANF) program (Fording et al., 2013). Non-compliant households would have their benefit levels reduced and eventually terminated. U.S. states, however, have discretion to implement various sanctions, such as reducing benefits for just the adult or for the entire family, and/or whether to impose a partial or full reduction of benefits. A majority of states have adopted especially severe sanctions that involve the total loss of benefits for both adults and children until the recipient complies with the work requirement (Floyd, Pavetti, \& Schott, 2015). Specific work requirements also vary by state, but TANF stipulates that states must have half of participants involved in work activities for at least 30 hours per week (or 20 hours for single parents with small children) or face a fiscal penalty.

Research on welfare reform impacts consistently find that the percentage of TANF-eligible families participating in the program has decreased dramatically since its implementation. A recent U.S. Government Accountability Office report, for example, indicates that eligible families receiving TANF decreased from 84 percent to 40 percent (Brown, 2010), and there is general agreement that the work sanctions have greatly contributed to the overall decline in client caseloads (Fording, 2013). Recent research has shown that TANF work requirements have had a greater effect in reducing welfare rolls than time limits (also authorized through PRWORA), and that "[i]n FY 2010, 260,000 families had their 
TANF case benefits ended because of refusal to comply with work requirements" (Falk et al., 2014, pp. 1920).

Research on the impacts of sanctions on clients, however, has been less clear (Fording et al., 2013). The best-designed studies generally find that sanctioned clients experience lower earnings and greater hardship after exiting the program compared to unsanctioned clients. In analyzing longitudinal data from Florida, Fording et al. (2013, p. 669) report that "sanctioning has a statistically-significant negative effect on earnings among TANF clients" when compared to a matched sample of non-sanctioned clients.

Regarding the characteristics of sanctioned households, Hasenfeld et al. (2004) found that sanctioned welfare recipients in California are more likely to be disadvantaged and face more barriers to compliance compared to non-sanctioned ones. In particular, sanctioned recipients were more likely to be younger, have more children, lack a car, or have a disabled household member. They conclude that work requirement compliance is closely related to barriers to employment, not resistance to the policy. In addition, they suggest that when welfare policies acknowledge and accommodate these barriers, impacted recipients are less likely to face sanctions. They also argue that practices of local welfare offices are a significant factor in the sanctioning of recipients. Thus, it is not just the sanctions themselves but how they are administered that may determine their impacts.

Based on the research outlined above, we expect that public housing work requirements would have negative impacts on employment and earnings due to increased housing instability. Furthermore, we would expect that the most vulnerable program participants are most likely to face sanctions and potential eviction. As noted by Hasenfeld et al. (2004), however, if work requirements are specified and implemented in a manner that recognizes and addresses barriers to compliance, these policies may have a positive impact on employment without increasing the rate of tenant evictions.

\section{Experience with work requirements}

\section{Moving to Work demonstration}

Several PHAs have implemented work requirements through participation in HUD's Moving to Work demonstration program. Authorized by Congress in 1996, Moving to Work (MTW, P.L. 104-134) provides PHAs the ability to explore innovative ways of providing decent and affordable housing to lowand moderate-income households (Abravanel et al., 2004). MTW has three statutory goals: (1) increase housing choices for low-income households, (2) assist participating households in achieving self-sufficiency, and (3) deliver services in more cost-effective ways. To achieve these goals, participating PHAs are provided two flexibilities. First, they may combine their primary federal funding streams - such as

operating, Housing Choice Voucher Program, and capital improvement funds - into a single, flexible 
account. Second, PHAs may request waivers from various HUD regulations, such as how often to inspect voucher holders' units or whether to introduce a work requirement.

Among the 39 PHAs participating in MTW as of July 2015, eight have implemented work requirements; 5 participants subject to these policies must work a specified amount or face sanctions (Webb et al., 2015). ${ }^{6}$ Required work efforts vary between 15 and 30 hours per week, and sanctions for non-compliance include reductions in housing subsidy (i.e., higher rents) and/or eviction. Most PHAs with work requirements allow households to fulfill the policy - at least for a limited time - through education, job training, or other work-related activities. Despite MTW's classification as a demonstration program, HUD has not sponsored any systematic evaluation of work requirement impacts.

\section{CHA's work requirement}

The Charlotte Housing Authority (CHA) joined MTW in December 2007, and has implemented several major initiatives through the program (Rohe, Webb, \& Frescoln, 2015). These include rent reforms - including a $\$ 75$ minimum rent and incentive accounts for all residents, diversifying its housing portfolio by partnering with other agencies to develop supportive housing for the homeless, and a work requirement paired with on-site case management in five of its 15 public housing (Section 9) developments.

The CHA's work requirement stipulates that work-able heads of household are employed at least 15 hours per week. The CHA provides on-site case managers to help residents meet the work requirement, such as referring them to job placement programs. Residents may use "work-related activities" to fulfill the policy; these include community service, educational courses, and/or job training. Non-compliant residents face rent sanctions. These include, in order: (1) a two-month probationary period, ${ }^{7}(2)$ losing half their rental subsidy for six months, (3) complete loss of rental subsidy for six months, and (4) eviction. Residents may eliminate sanctions at any point by coming into compliance, either by working or completing work-related activities through an "Improvement Plan," which entails weekly meetings with their case managers.

${ }^{5}$ Atlanta, Champaign County (IL), Charlotte, Chicago, the Delaware State Housing Authority, Lawrence-Douglas County (KS), Louisville, and San Bernardino.

${ }^{6}$ Several other MTW agencies have implemented policies that function as quasi-work requirements - such as raising minimum rents to a level (e.g., $\$ 200$ per month) - whereby tenants would almost certainly need some wage income to meet the rent payment. Note, however, that these policies do not require PHAs to verify whether participants are employed.

7 The two-month period is to provide legal notice to the tenant that his/her rent will be increased, and to complete the necessary administrative tasks. The CHA provided a one-time three-month probationary period at the beginning of sanctions. 
Among the five work requirement sites, two (Claremont and Victoria Square) previously housed only participants in the CHA's FSS program. As such, residents had applied to and been accepted into the FSS program, had relocated to these developments, and were receiving on-site case management prior to work requirement implementation. The other three sites (Cedar Knoll, Leafcrest, and Tarlton Hills) were not FSS sites; residents of these developments were not participating in any self-sufficiency program when the work requirement was introduced. Instead, the CHA selected these sites because of their proximity to both transit and employment opportunities. The agency did not allow residents to transfer to non-work requirement developments prior to implementation, and began providing case management at these sites in September 2011.

The CHA initially planned to enforce the work requirement in September 2012, one year after beginning case management at the non-FSS sites. However, high unemployment rates in Charlotte and staff turnover caused the CHA to delay enforcement until January 2014. Households received notification in October 2013 that enforcement would begin in January, and all non-compliant households were urged to find employment either on their own or with help from their case manager. Prior to implementing sanctions, case managers reassessed residents' work ability and temporarily exempted 32 households (of 139 eligible) from the policy while they sought disability status.

\section{Evaluation Design}

Adopting Cook and Campbell's (1979) terminology and notation, our evaluation uses a modified "untreated comparison group with pretest and posttest" research design. The design is:

$\begin{array}{llllll}\text { Treatment Group: } & \mathrm{O}_{1} & \mathrm{X}_{1} & \mathrm{O}_{2} & \mathrm{X}_{2} & \mathrm{O}_{3} \\ \text { Comparison Group: } & \mathrm{O}_{1} & & \mathrm{O}_{2} & & \mathrm{O}_{3}\end{array}$

Where: $\mathrm{O}$ denotes observations and $\mathrm{X}$ denotes treatments. Observations (data collection) of our dependent variables took place during three time periods for both the Treatment and Comparison Groups. The first treatment $\left(\mathrm{X}_{1}\right)$ was the introduction of case management and enhanced services in September 2011. The second treatment $\left(\mathrm{X}_{2}\right)$ was the introduction of sanctions for non-compliant households in January 2014.

Analysis comprises difference-in-differences tests of work outcomes between the Treatment and Comparison Groups between $\mathrm{O}_{1}$ and $\mathrm{O}_{2}$, and between $\mathrm{O}_{2}$ and $\mathrm{O}_{3}$. To control for households entering and leaving the CHA, we construct a panel dataset of families living in CHA housing in both September 2011 and December 2014. If case management was effective in increasing employment, we would expect to see significantly greater employment gains for the Treatment Group between $\mathrm{O}_{1}$ and $\mathrm{O}_{2}$ relative to the Comparison Group. If the combination of case management, services, and sanctions were effective, we 
would expect to see significantly greater employment gains between $\mathrm{O}_{2}$ and $\mathrm{O}_{3}$ for the Treatment Group versus the Comparison Group.

As mentioned above, the Treatment and Comparison Groups were not equivalent at baseline - $\mathrm{a}$ common problem with quasi-experimental research. Residents of Claremont and Victoria Square had opted in to the FSS program and were receiving case management and supportive services prior to work requirement implementation. In the analysis presented below, we refer to this group as Treatment Group A.

In contrast, residents of the non-FSS developments had not made any affirmative choice to move toward self-sufficiency. We refer to this group as Treatment Group B. Given the different histories and characteristics of residents of these two sets of developments, the data analysis will consider them both together and separately.

One would expect that residents in both treatment subgroups and in the Comparison Group (i.e., non-work requirement developments) have different household characteristics (see Table 1). To address these differences, we employ nearest-neighborhood propensity score matching using income sources (e.g., wages, disability, medical allowances) and household size at the beginning of the study period. Given the size disparity between the Comparison and Treatment Groups - in addition to relatively small size of the Treatment Groups - we use 3:1 matching without replacement (Guo \& Fraser, 2010; Rosenbaum \& Rubin, 1985). Table 1 compares both the Treatment and Comparison Groups on both household size and income sources at the beginning of the study period. Difference-of-means t-tests reveal that the matched Comparison and Treatment Groups are not significantly different on any of the characteristics analyzed. However, because differences between the Control and Treatment Groups continue to exist, we utilize several of these characteristics as controls in the difference-in-differences regressions.

Table 1: Descriptive statistics of treatment group and matched and unmatched control groups
\begin{tabular}{|l|c|c|c|}
\hline Variable & $\begin{array}{c}\text { Unmatched control } \\
\mathbf{N}=341\end{array}$ & $\begin{array}{c}\text { Matched control } \\
\mathbf{N}=219\end{array}$ & $\begin{array}{c}\text { Treatment } \\
\mathbf{N}=73\end{array}$ \\
\hline Household size & 2.93 & 3.16 & 3.01 \\
Wage income & $\$ 2,934^{\star}$ & $\$ 3,890$ & $\$ 4,633$ \\
Non-wage income & $\$ 2,302$ & $\$ 2,534$ & $\$ 3,024$ \\
Total income & $\$ 5,237^{\star *}$ & $\$ 6,253$ & $\$ 6,988$ \\
Total allowances & $\$ 1,739$ & $\$ 1,824$ & $\$ 1,664$ \\
Adjusted income & $\$ 3,805^{\star *}$ & $\$ 4,760$ & $\$ 5,613$ \\
\hline * - Significant difference with treatment group at $\alpha=0.10$ \\
\hline \multirow{2}{*}{ * - Significant difference with treatment group at $\alpha=0.05$} \\
\hline
\end{tabular}

\section{Data sources}

This paper draws upon data from four sources. First, we utilize CHA administrative data specifically from the Multifamily Tenant Characteristics System (MTCS) - which report households' size, 
income from various sources (e.g., wages, child support, pensions, and social security), and rent paid. However, when the CHA implemented biennial income re-certifications in October 2013, it ceased reporting household income changes between re-certifications. For those tenants paying minimum rent (\$75), however, the CHA continues to verify their income monthly. As such, we utilize minimum rent as a proxy for employment in one of the subsequent analyses. ${ }^{8}$ As mentioned earlier, to control for households entering and leaving the CHA, we construct a panel dataset of families living in CHA housing in both September 2011 and December 2014. We also source sanctions for non-compliance and the number and reasons for tenants leaving the $\mathrm{CHA}$ (e.g., evictions) from administrative data.

Second, we analyze End-of-Month (EOM) data collected by on-site case managers to track residents' work efforts. Unlike the MTCS, EOM data includes information on whether a client is working and, if so, the number of hours worked per week. We similarly construct a panel of residents living with the CHA in December 2012 and December 2014 for EOM data analysis. While there is no comparable data for residents in the Comparison Group, EOM data provide direct information on employment changes over time.

Third, we draw on responses from two population surveys of tenants of the CHA's family conventional public housing (Section 9) developments conducted in 2013 (when the work requirement had been announced but not yet enforced) and 2015 (roughly one year after beginning enforcement). The surveys queried respondents' perceptions of, and responses to, the work requirement. The 2013 survey received 548 responses for a return rate of 54 percent, while 519 households returned the 2015 survey for a response rate of 53 percent.

Finally, we present data from 43 in-person interviews with CHA residents living in the five work requirement sites. These interviews covered topics including resident responses to the work requirement, perceptions of its fairness, and satisfaction with case management.

\section{Findings}

\section{MTCS analysis}

We begin analysis of the MTCS panel data by graphing the percentage of minimum renters between a baseline of September 2011 (when case management began for Treatment Group B) and

\footnotetext{
${ }^{8}$ Households who are minimum renters earn less than $\$ 3,000$ annually in total income, adjusted for various allowances (e.g., out-of-pocket medical expenses or elderly/disabled household members). Residents may cease being a minimum renter for several reasons, including gaining employment or beginning to earn benefits, such as welfare or disability. As case managers work with residents to both gain employment and enroll in appropriate benefits programs, we feel that paying minimum rent is a good proxy of the effectiveness of supportive services and the work requirement.
} 
December 2014 (see Figure 1). At baseline, 54 percent of Comparison Group households paid minimum rent; this figure fluctuated modestly between 62 percent (in June 2012) and 51 percent (in December 2013) but stood at 55 percent in December 2014, one percentage point higher than baseline. For Treatment Group B - the non-FSS sites - 61 percent of households paid minimum rent at baseline, but that figure declined to 31 percent by December 2014. As one would expect, fewer Treatment Group A residents paid minimum rent at baseline (31\%). That figure rose to 45 percent in September 2012 before decreasing to 24 percent in December 2014. The decline in minimum renters among Treatment Group B was relatively steady throughout the study period but accelerates after enforcement of the work requirement. The decline in minimum renters among Treatment Group A also accelerates after March 2014, one quarter after work requirement enforcement began.

Figure 1: Percent of Comparison and Treatment Group households paying minimum rent, September 2011December 2014. Line denotes work requirement enforcement.

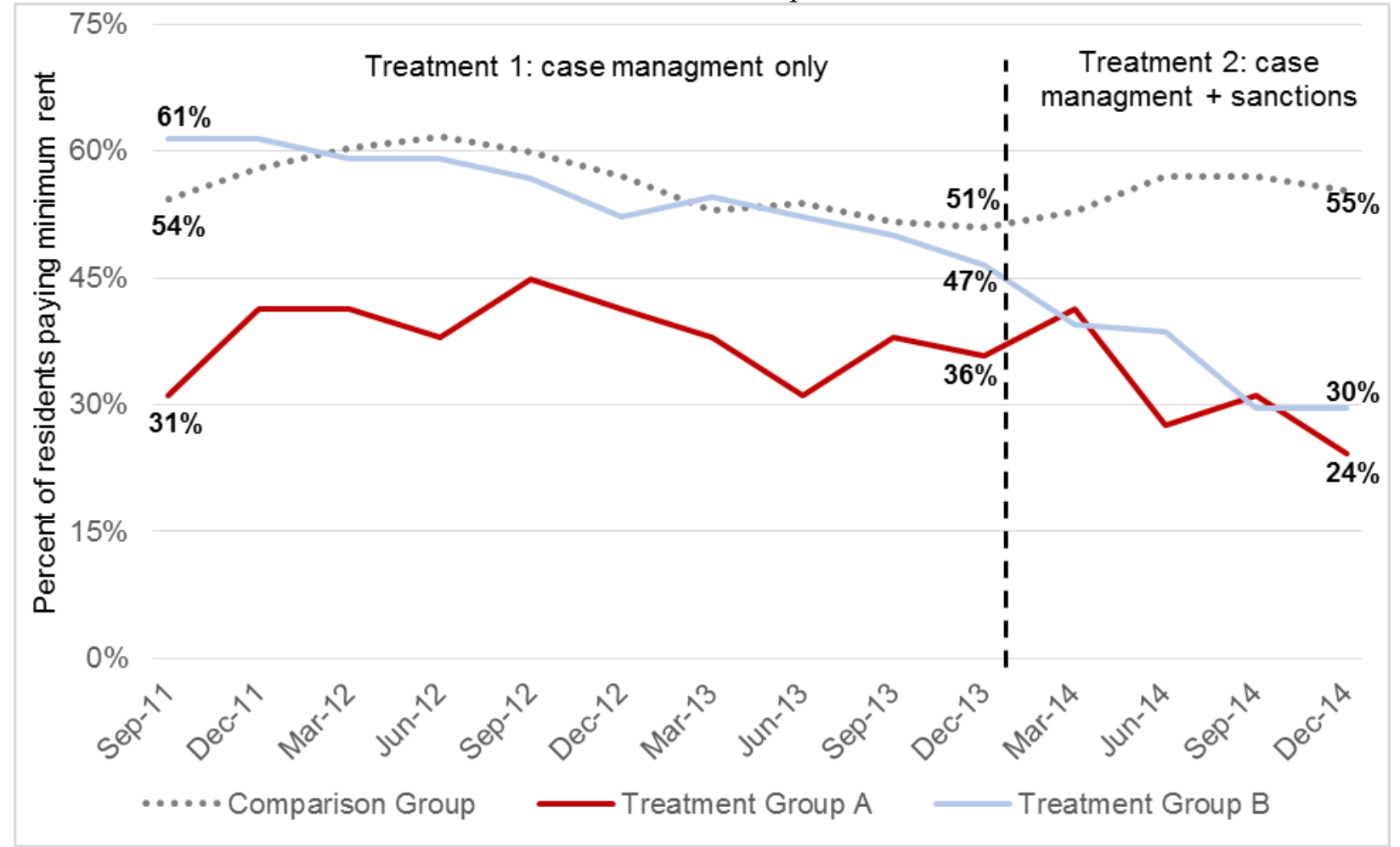

To test whether the introduction of Treatment 1 - on-site case management and supportive services - had a statistically-significant impact on the percentage of minimum renters, we conduct a difference-in-differences analysis between both Treatment Groups and the Comparison Group from September 2011 to December 2013 - the month before work requirement enforcement began. The change in minimum renters among the Comparison Group was minus 3 percent over this time period, while for Treatment Group B it was minus 14 percent, an 11 point difference of differences (see Figure 1). The percent of Treatment Group A residents paying minimum rent actually increased by 5 percentage points. 
A regression model testing whether the difference-of-differences between each of the Treatment Groups and the Comparison Group - controlling for baseline indicators of adjusted income, age, and household size - indicates that changes in minimum renters for both Treatment Groups are not significantly different from those of the Comparison Group (see Table 2). This indicates that on-site case management alone did not decrease the percentage of minimum renters in the two Treatment Groups in a statistically-significant manner.

Table 2: Difference-in-differences test of Treatment 1 (case management alone) on Comparison and Treatment Groups. Treatment variables that are statistically significant are in bold.

\begin{tabular}{|c|l|c|c|c|c|}
\hline \multicolumn{2}{|l|}{ Variable } & B & Beta & t & sig \\
\hline \multirow{2}{*}{ Treatment } & If in Treatment Group A & 0.01 & 0.00 & 0.07 & 0.95 \\
& If in Treatment Group B & 0.07 & 0.05 & 0.83 & 0.41 \\
\hline \multirow{3}{*}{ Controls } & Adjusted income & -0.03 & -0.40 & -7.17 & 0.00 \\
& Age & 0.00 & -0.08 & -1.30 & 0.19 \\
& Household size & -0.02 & -0.05 & -0.83 & 0.41 \\
& (Constant) & 0.41 & & 2.56 & 0.01 \\
\hline
\end{tabular}

In contrast, a difference-in-differences test indicates that Treatment 2 - work sanctions in addition to case management - did have a statistically-significant impact on the proportion of minimum renters (see Table 3). Between December 2013 (one month before sanctions began) and December 2014, the percentage of Comparison Group minimum renters increased by 4 percent, while the percentage among Treatment Group B decreased by 17 percent, a 21 point difference in differences. The percentage of minimum renters among Treatment Group A decreased by 12 percent resulting in a 16 point difference in differences. The regression model indicates a statistically-significant difference in the decreases between the Comparison Group and both Treatment Groups.

Table 3: Difference-in-differences test on outcome of Treatment 2 (case management and work requirement enforcement) on Treatment and Comparison Groups. Treatment variables that are statistically significant are in bold.

\begin{tabular}{|c|l|c|c|c|c|}
\hline \multicolumn{2}{|l|}{ Variable } & B & Beta & t & sig \\
\hline \multirow{2}{*}{ Treatment } & If in Treatment Group A & $\mathbf{0 . 2 3}$ & $\mathbf{0 . 1 5}$ & $\mathbf{2 . 5 4}$ & $\mathbf{0 . 0 1}$ \\
& If in Treatment Group B & $\mathbf{0 . 2 3}$ & $\mathbf{0 . 1 8}$ & $\mathbf{3 . 0 5}$ & $\mathbf{0 . 0 0}$ \\
\hline \multirow{3}{*}{ Controls } & Adjusted Income (000s) & -0.01 & -0.15 & -2.58 & 0.01 \\
& Age & 0.01 & 0.12 & 1.88 & 0.06 \\
& Household size & 0.04 & 0.11 & 1.81 & 0.07 \\
& (Constant) & -0.31 & & -2.07 & 0.04 \\
\hline
\end{tabular}

\section{EOManalysis}

Results of EOM data analysis - which reports hours worked for those receiving case management - are consistent with the MTCS results presented above: the percentage of employed residents in both Treatment Groups A and B increased substantially following work requirement enforcement in January 2014 (see Figure 2). The average hours worked among employed households, however, did not show a 
similar increase; it remains between 25 and 30 despite the additional households working. ${ }^{9}$ Unlike the MTCS data presented above, EOM data is only collected for those at the work requirement sites, and thus no Comparison Group data is available.

Figure 2: Employment for residents active in case management. Line denotes work requirement enforcement.

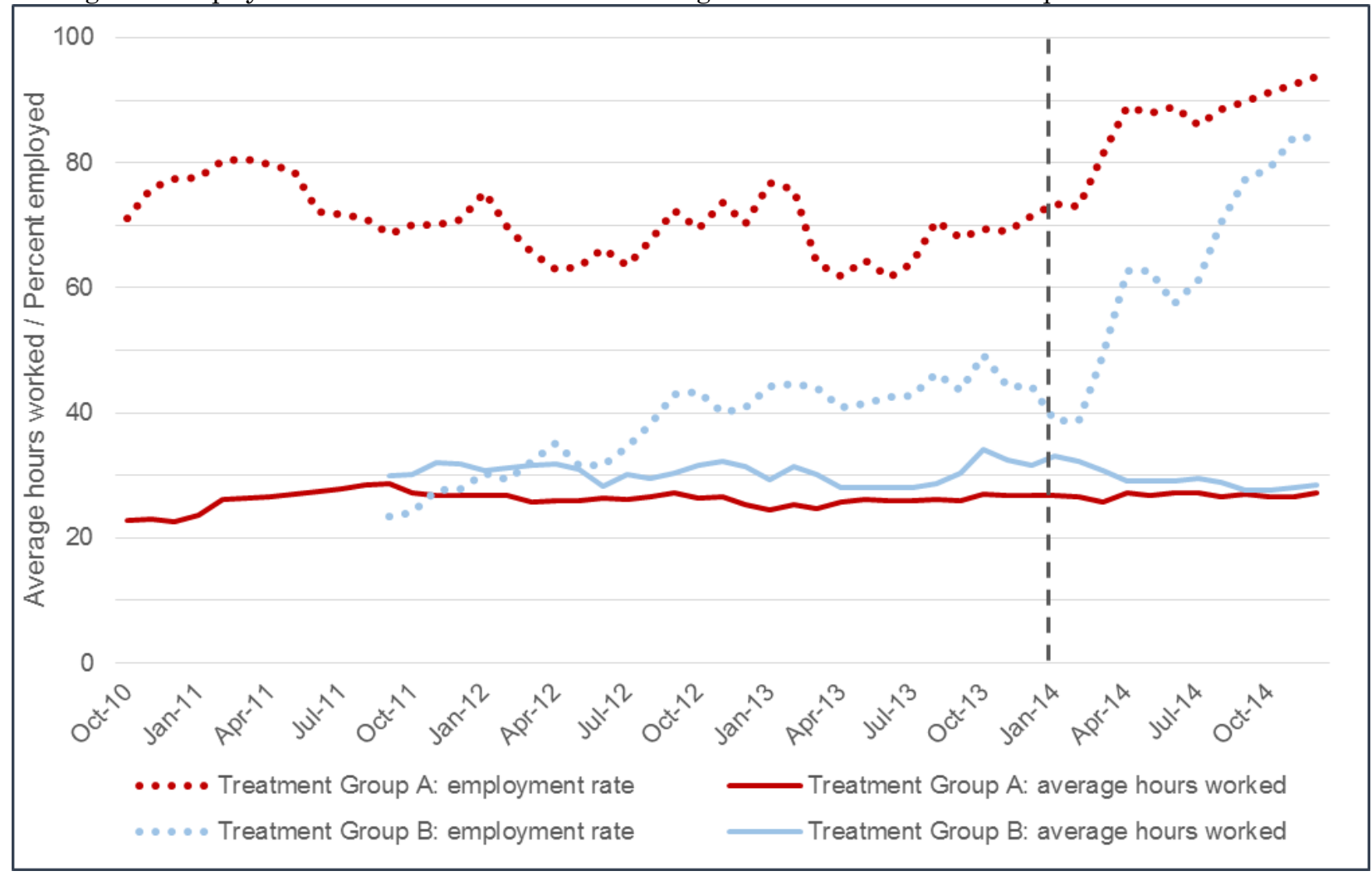

To test whether Treatments 1 and/or 2 resulted in statistically-significant employment gains, we utilize a McNemar test of marginal homogeneity to evaluate changes in EOM-reported employment for the 12-month periods both prior to and following work requirement enforcement (December 2012December 2013 and December 2013-December 2014, respectively). We draw on panel data of work requirement residents between December 2012 and December 2014. The McNemar test analyzes changes in proportions of dichotomous characteristics (such as working or not working) on data and is thus appropriate for this analysis (Rice, 1995).

\footnotetext{
${ }^{9}$ In additional analyses (available from the authors), we examined average hours worked between those employed before work requirement enforcement and those who gained employment following enforcement. We found that, among those previously working, hours worked did not increase following work requirement enforcement for either Treatment Group A or B (between 30-35 and 25-30 hours, respectively). Those gaining employment following enforcement worked slightly fewer hours, on average, than households previously employed (between 25-30 hours for Treatment Group A and 20-25 hours for Treatment Group B).
} 
In December 2012 - one year prior to the introduction of sanctions ${ }^{10}$ and 15 months following the beginning of case management - 51.3 percent (39 of 76) of work requirement residents were employed (see Table 4, top panel). While this figure increased to 58 percent (44 of 76) in December 2013 immediately before enforcement of the work requirement - this gain is not statistically significant (McNemar statistic of 1.19, p=0.353). However, by December 2014, 88 percent (67 of 76) of work requirement residents were employed; this increase over December 2013 figures is statistically significant at the $\alpha=0.001$ level (see Table 4 , bottom panel). These results support findings from the MTCS analysis: case management alone did not result in statistically-significant increases in work efforts, while case management combined with work requirement enforcement did coincide with significant employment gains.

Table 4: McNemar test on employment rates, December 2012-December 2013 and December 2013-December 2014

\begin{tabular}{|c|c|c|c|c|c|}
\hline \multirow{6}{*}{ 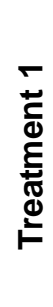 } & & & \multicolumn{2}{|c|}{ December 2013} & \multirow[b]{2}{*}{ Total } \\
\hline & \multirow{3}{*}{\begin{tabular}{|c} 
December \\
2012
\end{tabular}} & & Unemployed & Employed & \\
\hline & & Unemployed & 24 & 13 & 37 \\
\hline & & Employed & 8 & 31 & 39 \\
\hline & \multicolumn{2}{|c|}{ Total } & 32 & 44 & 76 \\
\hline & \multicolumn{5}{|c|}{$\begin{array}{l}\text { McNemar statistic: } 1.19 \\
p=0.383\end{array}$} \\
\hline \multirow{6}{*}{ 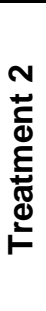 } & & & \multicolumn{2}{|c|}{ December 2014} & \multirow[b]{2}{*}{ Total } \\
\hline & & & Unemployed & Employed & \\
\hline & December & Unemployed & 7 & 25 & 32 \\
\hline & 2013 & Employed & 2 & 42 & 44 \\
\hline & \multicolumn{2}{|c|}{ Total } & 9 & 67 & 76 \\
\hline & \multicolumn{5}{|c|}{ McNemar statistic: 19.59} \\
\hline
\end{tabular}

\section{Work requirement compliance, sanctions, and move-outs}

To investigate compliance and sanctions associated with the work requirement, we turn to $\mathrm{CHA}$ enforcement data. The data indicate that a large majority of residents are compliant with the work requirement and that compliance has increased substantially over time (see Figure 3). While 25 and 26 non-compliant residents were placed on an Improvement Plan (i.e., they were non-compliant but had no rent sanction) in April and May, this number decreased to seven in June and remained under ten throughout the remainder of 2014. The number of residents remaining non-compliant for more than three months and, thus, receiving a 50 percent rent sanction varies between two and four; all told, only six

\footnotetext{
${ }^{10}$ Note that, at this time, residents were unaware when the CHA would begin enforcing the work requirement in January 2014.
} 
unique residents were sanctioned between July and December 2014. Of those households, only one was evicted due to non-payment of the increased rent.

Figure 3: Work requirement sanctions levied, April-December 2014

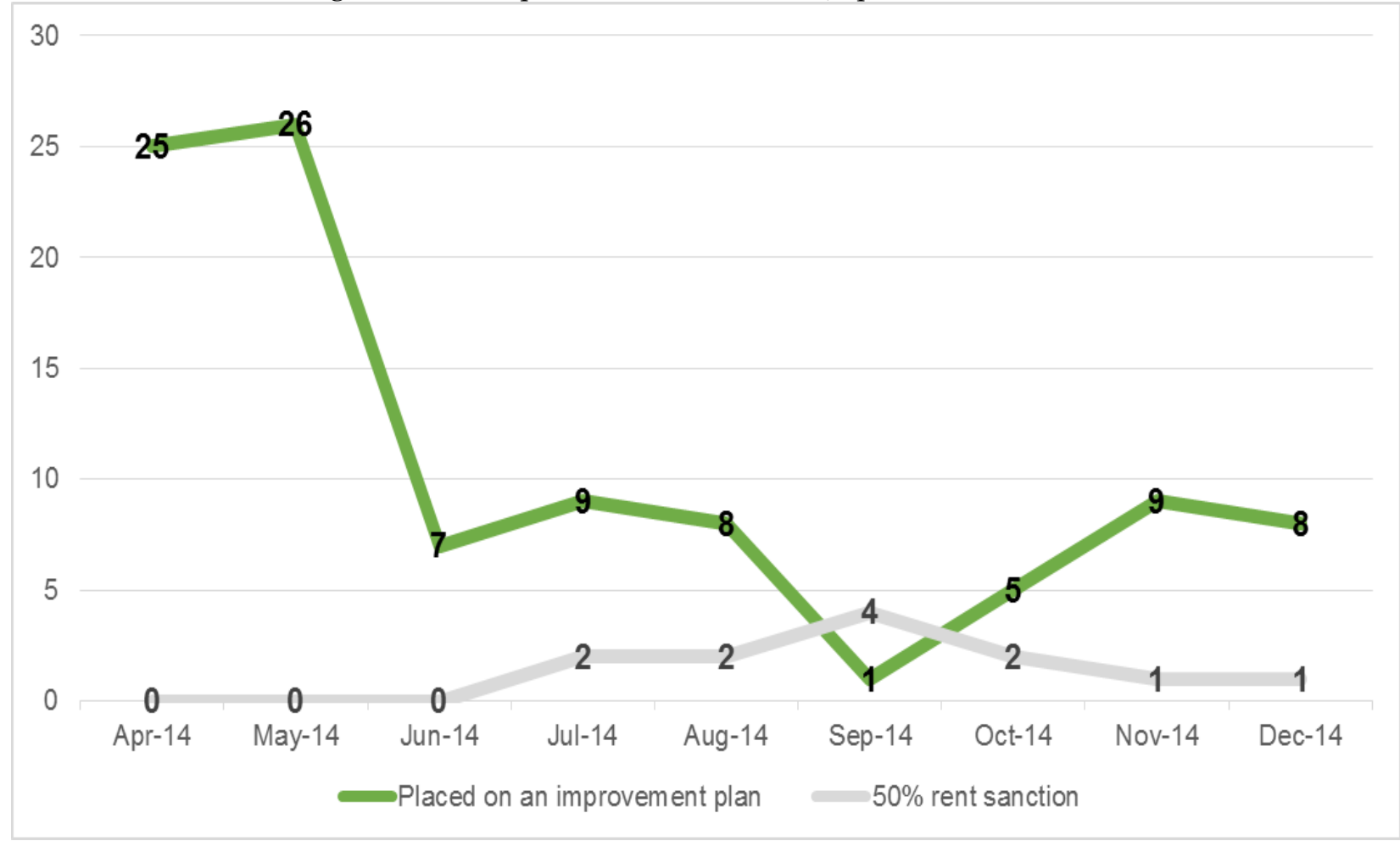

The decrease in households on Improvement Plans in June 2014 is due to 14 completing workrelated activities, three gaining employment, and two receiving disability status. Among those transitioning to work-related activities in June, eight later gained employment in 2014.

As discussed earlier, work requirement proponents hope these policies will increase positive moveouts from public housing, thus freeing up units for households on often-lengthy PHA waitlists. In contrast, policy opponents fear that work requirements will result in greater evictions, especially for the most vulnerable residents.

To compare the number and rate of positive and negative move-outs in both work requirement sites and other CHA public housing (Section 9) developments, we compare data in both 2013 (the year prior to work requirement enforcement) and 2014 (the year following enforcement). Positive move-outs occur when CHA tenants move to unsubsidized housing, while negative move-outs (i.e., evictions) follow failure to pay rent, violating lease terms, or moving without notice.

We find that positive move-outs increased for the former FSS sites (Treatment Group A) from 1.2 percent of tenants in 2013 to 8.5 percent in 2014 (see Table 5). However, we did not find this increase for the non-FSS work requirement sites. The positive move-out rate for households not subject to the work 
requirement increased modestly, from 1.0 percent to 1.2 percent. While we find some evidence that work requirement enforcement increased the rate of positive move-outs, we caution that the numbers presented here are small, and that this analysis does not use the panel data presented earlier.

Table 5: Move-out rates for CHA's public housing residents, 2013-2014

\begin{tabular}{|c|l|c|c|}
\hline Housing & $\begin{array}{c}\text { Type of } \\
\text { Move-out }\end{array}$ & $\begin{array}{c}\mathbf{2 0 1 3} \\
\# \text { (\%) }\end{array}$ & $\begin{array}{c}\mathbf{2 0 1 4} \\
\#(\%)\end{array}$ \\
\hline $\begin{array}{c}\text { Conventional } \\
\text { (Comparison Group) }\end{array}$ & Negative & $60(3.1)$ & $52(2.7)$ \\
\hline Former FSS & Negative & $20(1.0)$ & $23(1.2)$ \\
(Treatment Group A) & Positive & $6(7.3)$ & $0(0)$ \\
\hline Non-FSS & Negative & $8(1.2)$ & $7(8.5)$ \\
\hline (Treatment Group B) & Positive & $2(1.4)$ & $1(5.4)$ \\
\hline \multirow{2}{*}{ Total } & Negative & $74(3.4)$ & $60(2.8)$ \\
& Positive & $23(1.1)$ & $31(1.4)$ \\
\hline
\end{tabular}

Concerning negative move-outs, the eviction rate fell dramatically in Treatment Group A - from 7.3 percent in 2013 to 0 percent in 2014 - while it held steady for Treatment Group B (5.4\% in both years). The eviction rate for tenants not subject to the work requirement showed a modest decrease (from $3.1 \%$ to $2.7 \%$ ) over the two years. Thus, we find no evidence that work requirement enforcement increased the eviction rates for households subject to the policy.

\section{Resident views and responses}

To gauge support for work requirements among CHA residents, the 2013 client survey asked respondents if they felt work requirements for public housing residents were fair. We anticipated that support for the policy among residents subject to the work requirement would be lower than the support from those not impacted. Contrary to our expectations, 87 percent of residents subject to the work requirement believed the policy was fair compared to 80 percent of other public housing residents who felt the same way. Among those who did not believe the policy was fair, the most frequent reasons given were the lack of available jobs and difficulty securing employment.

The 2015 survey - conducted one year after work requirement enforcement - queried how residents had responded to the policy. Over half of all work-able respondents indicated that they had looked for a job, while over one-third reported they had found a new job (see Table 6). Slightly less than one-third indicated they had enrolled in a school or training program, and 22 percent reported they had begun working more hours. Finally, 19 percent of respondents indicated that they had not undertaken any of these activities. 
Table 6: Client actions in response to the work requirement (respondents could check more than one response)

\begin{tabular}{|l|c|}
\hline Response to work requirement & $\#(\%)$ \\
\hline Look for a new job & $33(52)$ \\
Find a new job & $23(37)$ \\
Enroll in a school or training program & $19(30)$ \\
Work more hours & $14(22)$ \\
None of the above & $12(19)$ \\
\hline
\end{tabular}

In-person interviews with residents subject to the work requirement also revealed broad support for the policy. One resident commented: "I just think if you have a roof over your head that's reasonable rent, you get help from all over the place, and you get transportation.... Work! That's just it." While most agreed that a work requirement is appropriate, many residents did not support evicting residents for not meeting that requirement, especially for circumstances beyond their control. For example, one resident worried that "[t]here may come a time when I have childcare issues and I lose my job. I pray that they are a little lenient towards those who are trying versus those that are not putting out the effort."

\section{Conclusions and policy implications}

In recent years, many have debated adopting public housing work requirements, and several PHAs have implemented these policies through MTW flexibility. To date, however, no systematic evaluation of work requirement outcomes has been conducted. This paper provides the results of the first research addressing this important issue.

Utilizing panel data to analyze a work requirement introduced by the Charlotte Housing Authority in five public housing (Section 9) developments, this paper has addressed three questions. First, did either case management alone or paired with a work requirement increase employment among residents versus those who did not receive these treatments? Comparing the percentages of households paying minimum rent - a proxy for employment - we find larger decreases in minimum renters among both Treatment Groups compared to the Comparison Group. That decrease, however, was only statistically significant following enforcement of the work requirement, not for the period when households were receiving case management alone.

End-of-Month data analysis on employment finds similar results: employment increased significantly following work requirement enforcement. Among those working, however, work requirement enforcement did not increase average hours worked. These results show that, by themselves, case management and enhanced services did not result in a statistically-significant increase in employment. The combination of case management and work requirement enforcement, however, did have such an impact.

Second, this paper has addressed whether work requirement enforcement led to sanctioning and/or increased eviction or positive move-out rates among impacted residents. We find that the number 
of sanctioned residents is low, and that compliance with the work requirement has increased over time. In fact, only six households received a rent sanction between May and December 2014, and only one household was evicted due to failure to pay the higher rent. We also find that the negative move-out rate among work requirement tenants declined between 2013 (pre-enforcement) and 2014 (post-enforcement), which was consistent with the pattern of negative move-outs in the non-work requirement sites. Similarly, the rate of positive move-outs from the work requirement sites increased between 2013-2014, which was consistent with CHA developments not subject to the work requirement.

Overall, we find no evidence that sanctions increased evictions or other forms of negative moveouts. This is likely due to the CHA's emphasis on helping tenants reach compliance instead of adopting a punitive approach. For example, the policy includes a two-month probationary period for residents to reach compliance, in addition to allowing certain work-related activities to substitute for paid employment. Thus, at least in this instance, the imposition of public housing work requirements has not had the same impacts as those imposed in the TANF program discussed above.

Finally, this paper has assessed residents' perceptions of the work requirement - is it fair? - and how those subject to the policy have responded to it. More than 80 percent of survey respondents including those impacted by the policy and those not subject to it - express general support for work requirements. Interviews of residents subject to the work requirement generally support this finding, although they would like to see the policy implemented flexibly. This finding suggests that most public housing residents have the same values concerning work as the larger society. Among those subject to the work requirement, over 80 percent of respondents indicated they had looked for employment, found a new or different job, enrolled in school or training, or worked more hours.

While these findings clearly support the effectiveness of the CHA's work requirement in increasing employment, our research has several limitations. For one, this study is not based on a random-controlled experimental design. Although we utilized propensity score matching to control for observed differences between the Treatment and Comparison Groups, unobserved characteristics could bias the results. The range of outcome variables is also limited: future research might assess work requirement impacts on mental or physical health, children's behavior, or other outcomes. Another limitation is that this study has only looked at the short-term outcomes, and we hope that future research tracks work requirement impacts over a longer time period. What happens, for example, when those who have found work lose their jobs? Will the same services be available to help them find a new one?

\section{Policy implications}

Given these limitations, we caution against drawing more general conclusions and believe it is premature to implement work requirements across the public housing program. In particular, several 
aspects of how the CHA implemented the policy may be essential to the positive results. First, the CHA provided on-site case management and supportive services for over two years prior to imposing sanctions, and those services continued following enforcement. Second, the CHA delayed enforcement until the local economy had rebounded from the recent recession. Third, the CHA temporarily exempted residents identified as potentially having disabilities (but not officially classified as disabled), providing them an opportunity to apply for disability status. Fourth, the CHA's sanctions allowed for a two-month probationary period (three months at the onset of sanctions) during which case managers worked with residents to achieve compliance. Moreover, the CHA allows residents to engage in "work-related activities" as short-term substitutes for paid employment. Overall, then, CHA staff members were focused on helping residents comply with the work requirement, not on evicting tenants.

These issues also highlight potentially large obstacles to bringing work requirements to scale. Costs associated with providing case management and enhanced services to those in the work requirement sites were substantial. As a MTW participant, the CHA could shift funds from other program areas to pay for these services, but most PHAs do not have this flexibility. Moreover, we don't know the type and amount of both case management and enhanced services that are needed to produce outcomes similar to those found in this study. How often should case managers communicate with tenants? Which services are most important to positive work outcomes, and how long are these services needed before sanctions are imposed? Implementing a work requirement without adequate supportive services may result in a much higher eviction rate. These and other questions should be addressed before work requirements are expanded to the entire public housing program.

We also note that work requirement enforcement did not increase the average hours worked among those subject to it. This suggests that, while the policy was effective in increasing employment, newly-gained jobs were likely to be part-time work. It also suggests that hours worked, and presumably incomes, of households employed prior to enforcement did not increase. Thus, at least in this instance, the work requirement did not result in the kind of financial impact that would allow many residents to move out of public housing. The rents collected by the CHA, however, should have increased and positively contributed to the agency's fiscal health. Whether the increase in employment was enough to meaningfully reduce concentrated poverty - or create a social milieu of work - is a question for future research.

The MTW program offers a good opportunity to conduct additional research on work requirements and other innovations in the public housing program. Unfortunately, this program has not been implemented in a way that has produced such evaluations. As Congress debates both the reauthorization and expansion of MTW, it should mandate that participating PHAs evaluate the impacts of the innovations that substantially affect residents, such as work requirements. Further, Congress 
should authorize additional funds to conduct such evaluations. Only through these means will we be able to understand the impacts of alterations in the public housing program on the tenants, PHAs, and the larger community. 


\section{Reference List}

Abravanel, M. D., Smith, R., Turner, M. A., Cove, E., Harris, L. E., \& Manjarrez, C. (2004). Testing Public Housing Deregulation: a summary assessment of HUD's "Moving to Work" demonstration. Washington, DC. Retrieved from http://www.urban.org/publications/311009.html

Bloom, H. S., Riccio, J. A., \& Verma, N. (2005). Promoting Work in Public Housing: The Effectiveness of Jobs-Plus. New York. Retrieved from http://www.mdrc.org/publication/promoting-work-publichousing

Bratt, R. G. (2002). Housing and Family Well-being. Housing Studies, 17(1), 13-26. doi:10.1080/02673030120105857

Bratt, R. G., Stone, M. E., \& Hartman, C. (Eds.). (2006). A Right to Housing: Foundation for a New Social Agenda. Philadelphia: Temple UP.

Briggs, X. de S., Popkin, S. J., \& Goering, J. (2010). Moving to Opportunity: The Story of an American Experiment to Fight Ghetto Poverty. New York: Oxford University Press.

Brown, K. E. (2010). Fewer Eligible Families Have Received Cash Assistance Since the 1990s, and the Recession's Impact on Caseloads Varies by State. GAO-10-164. Washington, DC. Retrieved from http:/www.gao.gov/new.items/d10164.pdf

Castro Ramirez, L. (2015). HUD's Jobs-Plus Pilot Program Connects Public Housing Residents with Employment and Educational Opportunities. The HUDdle. Retrieved July 7, 2015, from http://blog.hud.gov/index.php/2015/05/28/huds-jobs-plus-pilot-program-connects-public-housingresidents-employment-educational-opportunities/

Cook, T. D., \& Campbell, D. T. (1979). Quasi-Experimentation: Design \& Analysis Issues for Field Settings. Boston: Houghton Mifflin.

Couch, L. (2014). Public Housing: Moving to Work Demonstration Program. Washington, DC. Retrieved from http://nlihc.org/sites/default/files/2014AG-131.pdf

de Silva, L., Wijewardena, I., Wood, M., \& Kaul, B. (2011). Evaluation of the Family Self-Sufficiency Program: Prospective Study. Washington, DC. Retrieved from http://www.huduser.org/portal/publications/familyselfsufficiency.pdf

Edgar, B., Doherty, J., \& Meert, H. (2002). Access to Housing: Homelessness and Vulnerability in Europe. Bristol, UK: The Policy Press.

Falk, G., McCarty, M., \& Aussenberg, R. A. (2014). Work Requirements, Time Limits, and Work Incentives in TANF, SNAP, and Housing Assistance. Washington, DC. Retrieved from http://greenbook.waysandmeans.house.gov/sites/greenbook.waysandmeans.house.gov/files/R43400_ gb.pdf

Ficke, R. C., \& Piesse, A. (2004). Evaluation of the Family Self-Sufficiency Program: Retrospective Analysis, 1996 to 2000. Washington, DC. 
Fischer, W. (2015). HUD Seeks Significant Improvements to "Moving to Work" Demonstration, But Additional Changes Needed. Washington, DC. Retrieved from http://www.cbpp.org/files/1-2115hous.pdf

Floyd, I., Pavetti, L., \& Schott, L. (2015). TANF Continues to Weaken as a Safety Net. Washington, DC. Retrieved from http://www.cbpp.org/sites/default/files/atoms/files/6-16-15tanf.pdf

Fording, R. C., Schram, S. F., \& Soss, J. (2013). Do Welfare Sanctions Help or Hurt the Poor? Estimating the Causal Effect of Sanctioning on Client Earnings. Social Service Review, 87(4), 641-676. doi:10.1086/674111

Goetz, E. G. (2013). New Deal Ruins: Race, Economic Justice, and Public Housing Policy. Ithaca, NY: Cornell UP.

Graves, E. M. (2011). Mixed Outcome Developments. Journal of the American Planning Association, 77(2), 143-153. doi:10.1080/01944363.2011.567921

Guo, S., \& Fraser, M. W. (2010). Propensity score analysis: statistical methods and applications. Thousand Oaks, Calif: Sage Publications.

Hasenfeld, Y., Ghose, T., \& Larson, K. (2004). The Logic of Sanctioning Welfare Recipients: An Empirical Assessment. Social Service Review, 78(2), 304-319. doi:10.1086/382771

Joseph, M. L., Chaskin, R. J., \& Webber, H. S. (2007). The Theoretical Basis for Addressing Poverty Through Mixed-Income Development. Urban Affairs Review, 42(3), 369-409. doi:10.1177/1078087406294043

Kleit, R. G. (2005). HOPE VI new communities: neighborhood relationships in mixed-income housing. Environment and Planning A, 37(8), 1413-1441. doi:10.1068/a3796

Levitz, J. (2013, May 6). Public Housing Agencies Push to Impose Time Limits, Work Requirements for Aid Recipients. Wall Street Journal. New York. Retrieved from http://www.wsj.com/articles/SB10001424127887323820304578410382522144560

Lewis, O. (1959). Five Families: Mexican Case Studies in the Culture of Poverty. Basic Books.

Massey, D. S., \& Denton, N. A. (1993). American Apartheid: Segregation and the Making of the Underclass. Cambridge, MA: Harvard UP.

McClure, K., Schwartz, A. F., \& Taghavi, L. B. (2015). Housing Choice Voucher Location Patterns a Decade Later. Housing Policy Debate, 25(2), 215-233. doi:10.1080/10511482.2014.921223

Mead, L. M. (1998). Telling the poor what to do. The Public Interest, (Summer), 97-112.

Newman, S. J. (1999). From the Eye of the Housing Practicioner. In Newman (Ed.), The Home Front. Washington, DC: Urban Institute Press.

Office of Policy Development and Research. (1987). Project Self-Sufficiency: An Interim Report on Progress and Performance. Washington, DC. Retrieved from http:/hdl.handle.net/2027/mdp.39015029295287 
Olsen, E. O., Tyler, C. A., King, J. W., \& Carrillo, P. E. (2005). The Effects of Different Types of Housing Assistance on Earnings and Employment. Cityscape, 8(2), 163-187.

Omnibus Consolidated Rescissions and Appropriations Act of 1996. P.L. 104-134. 110 Stat. 1321 (1996).

Personal Responsibility and Work Opportunity Reconciliation Act of 1996. P.L. 104-193. 110 Stat. 2105 (1996).

Quality Housing and Work Responsibility Act of 1998. Title V of P.L. 105-276. 112 Stat. 2461 (1998).

Reingold, D. A., Van Ryzin, G. G., \& Ronda, M. (2001). Does Urban Public Housing Diminish the Social Capital and Labor Force Activity of Its Tenants? Journal of Policy Analysis and Management, 20(3), 485-504.

Riccio, J. A. (2008). Subsidized Housing and Employment: Building Evidence of What Works. In Revisiting Rental Housing: Policies, Programs, and Prioirities (pp. 191-224). Washington, DC: Brookings.

Rice, J. (1995). Mathematical Statistics and Data Analysis (2nd ed.). Belmont, California: Duxbury Press.

Rohe, W. M., \& Kleit, R. G. (1997). From Dependency to Self-Sufficiency: An Appraisal of the Gateway Transitional Families Program. Housing Policy Debate, 8(1), 75-108.

Rohe, W. M., \& Kleit, R. G. (1999). Housing, Welfare Reform, and Self-Sufficiency: An Assessment of the Family Self-Sufficiency Program. Housing Policy Debate, 10(2), 333-369.

Rohe, W. M., Webb, M. D., \& Frescoln, K. P. (2015). Moving to Innovation: the Charlotte Housing Authority's Moving Forward Program. Chapel Hill, NC.

Rosenbaum, P. R., \& Rubin, D. B. (1985). Constructing a Control Group Using Multivariate Matched Sampling Methods That Incorporate the Propensity Score. The American Statistician, 39(1), 33-38. doi:10.1080/00031305.1985.10479383

Schwartz, A. F. (2015). Housing Policy in the United States (3rd ed.). New York: Routledge.

Scirè, M. J. (2013). HUD Data on Self-Sufficiency Programs Should Be Improved. Washington, DC. Retrieved from http://gao.gov/assets/660/655797.pdf

Steffen, B. L., Carter, G. R., Martin, M., Pelletiere, D., Vandenbroucke, D. A., \& Yao, Y.-G. D. (2015). Worst Case Housing Needs: 2015 Report to Congress. Washington, DC. Retrieved from

http:/www.huduser.org/portal//Publications/pdf/WorstCaseNeeds_2015.pdf

Stockard, J. G., Byrne, G. A., Day, K., Maneval, G. A., Nielsen, L. A., \& James, K. (2003). Public Housing Operating Cost Study.

Stone, M. E. (1993). Shelter Poverty: New Ideas on Housing Affordability. Philadelphia: Temple UP.

Susin, S. (2005). Longitudinal Outcomes of Subsidized Housing Recipients in Matched Survey and Administrative Data. Cityscape, 8(2), 189-218. 
Turner, M., Popkin, S. J., \& Rawlings, L. (2009). Public housing and the legacy of segregation. Washington, DC: Urban Institute Press.

Vale, L. (2000). From the Puritans to the Projects: Public Housing and Public Neighbors. Cambridge, MA: Harvard UP.

von Hoffman, A. (2012). History lessons for today's housing policy: the politics of low-income housing. Housing Policy Debate, 22(3), 321-376. doi:10.1080/10511482.2012.680478

Webb, M. D., Frescoln, K. P., \& Rohe, W. M. (2015). Innovation in Public Housing: The Moving to Work Demonstration. Chapel Hill, NC. Retrieved from https://curs.unc.edu/files/2015/01/The-Moving-toWork-Demonstration-Center-for-Urban-and-Regional-Studies-Report.pdf

Wilson, W. J. (1987). The Truly Disadvantaged: The Inner-city, the Underclass, and Public Policy. Chicago: U Chicago Press. 